\title{
Comparative Evaluation of Waste Cooking Oil and Waste Engine Oil Rejuvenated Asphalt Concrete Mixtures
}

\author{
Abdullah Al Mamun ${ }^{1} \cdot$ H. I. Al-Abdul Wahhab ${ }^{2}$ - M. A. Dalhat ${ }^{3}$ \\ Received: 18 November 2019 / Accepted: 3 April 2020 / Published online: 22 April 2020 \\ (c) The Author(s) 2020
}

\begin{abstract}
In road construction, different types of waste oil have been recommended to overcome the stiffening effect of reclaimed asphalt pavement content. However, the selection of an effective rejuvenator based on a comparative study can lead to using the resources more efficiently. In this study, waste cooking oil and waste engine oil are used to rejuvenate three different percentages $(30 \%, 40 \%$, and $50 \%)$ of reclaimed asphalt pavement following the current maximum industrial adaptability. The waste oil rejuvenated mixtures are compared to the fresh mixture, and mixtures rejuvenated with commercial rejuvenator. The moisture sensitivity, indirect tensile strength, and resilient modulus of the various asphalt mixtures are analyzed. Based on the statistical analyses and overall ranking, it is concluded that $7 \%$ of waste engine oil performs better till $40 \%$ of reclaimed asphalt pavement, whereas $13 \%$ of waste cooking oil can be used till $50 \%$ of reclaimed asphalt pavement.
\end{abstract}

Keywords Asphalt binder $\cdot$ Reclaimed asphalt pavement $\cdot$ Rejuvenator $\cdot$ Waste cooking oil $\cdot$ Waste engine oil

\section{Introduction}

It has been established that the use of reclaimed asphalt pavement (RAP) in asphalt pavement construction leads to saving in material expenses, lower carbon emission, lower required energy consumption, lesser water utilization, etc. [1-3]. However, the use of a higher percentage of RAP ingredient (usually more than 20\%) in asphalt pavement becomes challenging due to its increased stiffness. The stiffness of RAP due to aging is the consequence of altered constituent, i.e., asphaltenes-to-maltenes ratio in the asphalt binder [4]. The uncontrolled use of RAP can lead to a stiffer mixture and subsequently ended up in a premature failure [5]. Therefore, the use of RAP in new asphalt pavement requires the rejuvenation of the lost properties. The traditional process of regaining the lost properties is carried out by adding a chem-

Abdullah Al Mamun

amamun@qu.edu.qa

1 Department of Civil and Architectural Engineering, Qatar University, Doha, Qatar

2 Department of Civil and Environmental Engineering, King Fahd University of Petroleum and Minerals, Dhahran, Saudi Arabia

3 Department of Transportation and Traffic Engineering, College of Engineering, Imam Abdulrahman Bin Faisal University, Dammam, Saudi Arabia ical recycling agent that counteracts the altered constituent of aged asphalt [6]. Chemical additives that blended into the asphalt mixture as rejuvenators are known as recycling agents. The recycling agent in a RAP-incorporated mixture restores the chemical composition of asphalt and provides consistency. Restoration of the lost properties of asphalt by countering the RAP-hardening effect may be achieved using different types of commercial rejuvenators (CRs) [7]. In addition to different CRs, the use of waste materials with similar characteristics was also reported [8].

There are many potential recycling agents that can rejuvenate the RAP, and one of the highly recommended agents is waste oil. Waste oils can be categorized differently according to their constituents and source. Among different types of waste oil, the potential of waste engine oil (WEO) and waste cooking oil (WCO) have been explored by many researchers [9-18]. These studies concluded that WCO and WEO can significantly affect different characteristics of asphalt mixture [19-21]. Other previous studies concluded that a better rejuvenating effect can be attained by providing a significant amount of aromatic fractions or resin [22], and recommended WEO and WCO base on different properties. However, most of these previous studies on WEO and WCO are independent and did not analyze the WEO and WCO comparatively. The only studies that attempted comparative analysis, either conducted their analysis based on self-predetermined reju- 


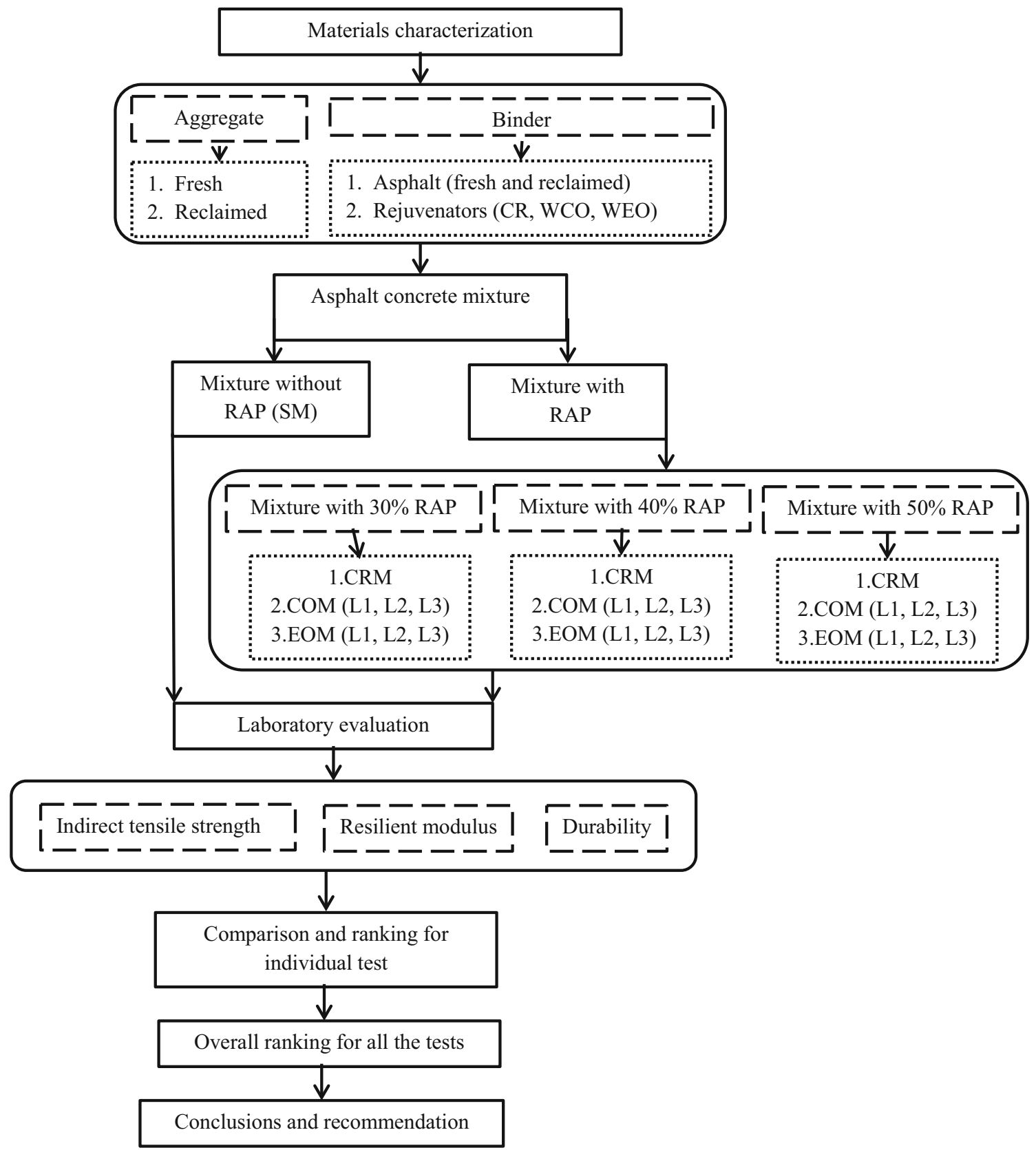

Fig. 1 Experimental design flowchart

venator content instead of the optimum [23], or conducted the analysis of the results independently, with little attention to relative comparison [24].

The selection of effective waste oil as a rejuvenator can lead to efficient use of resources and help towards a more sustainable pavement construction. However, the selection of a waste oil among these oils requires a comparative study of their performance for different properties. Therefore, the main objective of the study is to evaluate and compare different properties of the WCO and WEO rejuvenated asphalt concrete mixtures for high contents of RAP. To comparatively evaluate the effectiveness of RAP incorporated mixtures, the indirect tensile strength, resilient modulus, and moisture sensitivity of the fresh mixture, and the mixtures rejuvenated by the desired rejuvenators are measured. Based on the comparison, for a certain percentage of RAP, an optimal amount of waste oil is recommended.

\section{Experimental Program and Procedures}

Some of the major steps followed in the study can be observed in Fig. 1. 
The materials collected from different sources are evaluated according to their respective standard tests. This includes characterizations of binder (fresh and extracted asphalt, CR, WCO and WEO) and aggregate (fresh and reclaimed). The optimum binder content of all the mixtures with RAP rejuvenated by any of the rejuvenators (CR, WCO, and WEO) or without any RAP (denoted as SM) was estimated using the Marshall method of mixture design (ASTM-D1559). The RAP incorporated mixtures comprised of three distinct levels of RAP $(30 \%, 40 \%$, and $50 \%)$. Here, $50 \%$ percent of RAP is selected as a maximum considering industrial limit [25]. Mixture with a certain percentage of RAP comprises three different levels of each waste oil (L1, L2, and L3). Finally, the mixtures are evaluated in the laboratory for three different tests: Indirect Tensile Strength, Resilience Modulus, and Moisture Sensitivity as a function of Retained Strength Index. Based on these evaluated characteristics, the RAP incorporated mixtures were compared to the mixture without any RAP and ranked to find the most effective rejuvenator and its percentage. The details are discussed further in the following sections.

\section{Material}

All the materials used in the study were collected from the local asphalt plant in Dammam, Saudi Arabia. The RAP is evaluated by the ignition test (ASTM D6307) and is found to have an asphalt level of 5\%. Different properties of the binders are presented in Table 1.

The blending chart and viscosity of the binder (asphalt, WCO, WEO, CR) dictate the required amount of the corresponding binder in the mixture. The desired viscosity of the final binder is the viscosity of the fresh asphalt, which is obtained by adding 7\%, $13 \%$ and $20 \%$ of CR, WEO, and $\mathrm{WCO}$, respectively. In addition to that, two other percentages of WCO (13\% and 27\%) and WEO (7\% and 20\%) are also introduced. All the applied percentages of WCO and WEO are by the weight of the total reclaimed binder. In Table 2, the obtained properties of aggregate from RAP are subsequent to the solvent extraction method (ASTM D2172).

Table 1 Properties of asphalt and rejuvenator

\begin{tabular}{lll}
\hline Property & Specific gravity $(\mathrm{g} / \mathrm{cc})$ & $\begin{array}{l}\text { Viscosity @60 }{ }^{\circ} \mathrm{C} \\
\text { (poise) }\end{array}$ \\
\hline Fresh asphalt & 1.017 & 3980 \\
Reclaimed asphalt & - & 43,000 \\
WCO & 0.917 & 0.125 \\
WEO & 0.872 & 0.5 \\
CR & 0.860 & 0.3715 \\
\hline
\end{tabular}

Table 2 Specific gravity of aggregate

\begin{tabular}{llll}
\hline $\begin{array}{l}\text { Specific gravity } \\
\text { type }(\mathrm{g} / \mathrm{cc})\end{array}$ & Type of aggregate & Fresh aggregate & RAP \\
\hline Bulk & Coarse & 2.503 & 2.425 \\
& Fine & 2.53 & 2.575 \\
\multirow{2}{*}{ Apparent } & Coarse & 2.678 & - \\
& Fine & 2.575 & - \\
\hline
\end{tabular}

RAP is enriched in finer aggregate; therefore, previous studies suggested to use a higher amount of coarse portion of RAP for the final gradation of a mixture [26]. Table 3 indicates the final gradation for all the mixtures that follow the specification by the Ministry of Transport in Saudi Arabia. It was obtained by adding a constant gradation of RAP and different percentages of fresh aggregate. The same gradation was also adopted for the mixture without any RAP.

\section{Preparation and Evaluation of Specimens}

The study comprises four different types of mixtures. All the RAP-incorporated mixtures comprised the corresponding rejuvenator and required amount of binder, fresh aggregate following the percentage of RAP in the mixture. The study follows the Marshall mix design (ASTM-D1559) method in preparing the specimens, and the details are summarized below.

\subsection{Mixture Fabrication}

The study optimizes the mixture following the Marshall mix design method (ASTMD1559) that optimizes the mixture based on the Marshall criteria. Each of the RAP incorporated mixtures comprises a predefined percentage of the modifier, RAP, fresh asphalt and aggregate. To prepare the mixture, at first the fresh aggregate and asphalt, and the RAP was heated individually for $2 \mathrm{~h}$ at $146{ }^{\circ} \mathrm{C}$. The heating period is considered as the standard procedure [27]. At the end of $2 \mathrm{~h}$, the constituents were mixed properly by the mixer, and finally it was compacted by 75 blows on each side. The percentages of $\mathrm{CM}$, WEO, and WCO used in the mixtures were $7 \%, 13 \%$, and $20 \%$ respectively. The optimum asphalt level is subject to change depending on the type of rejuvenator. However, for a certain percentage of RAP in the mixture, the observed insignificant differences in optimum asphalt levels due to different rejuvenators were adjusted by keeping similar asphalt level. The optimum asphalt level for fresh mixture is $6.1 \%$, whereas the value is $5.5 \%, 5.2 \%$, and $5.0 \%$ for $30 \%, 40 \%$, and $50 \%$ of RAP, respectively. All the mixtures followed the specification mentioned in Table 4. 
Table 3 Asphalt concretes aggregate gradation

\begin{tabular}{lcccc}
\hline Sieve size & RAP aggregates & Virgin aggregate & Combined & Specification \\
\hline No. $3 / 4$ & 100.0 & 100.0 & 100.00 & 100.00 \\
No. $1 / 2$ & 15.0 & 72.22 & 85.83 & $76.00-92.00$ \\
No. $3 / 8$ & 5.0 & 40.28 & 69.58 & $64.00-79.00$ \\
No. 4 & 0.0 & 12.50 & 50.00 & $41.00-56.00$ \\
No. 10 & 0.0 & 6.67 & 32.92 & $23.00-37.00$ \\
No. 40 & 0.0 & 4.44 & 18.33 & $7.00-20.00$ \\
No. 80 & 0.0 & 2.22 & 11.67 & $5.00-13.00$ \\
No. 200 & 0.0 & 0.50 & 6.50 & $3.00-8.00$ \\
\hline
\end{tabular}

Table 4 Specification for Marshall properties

\begin{tabular}{ll}
\hline Properties & Specification \\
\hline Stability $(\mathrm{kg})$ & 800 (minimum) \\
Stability loss $(\%)$ & 20 (maximum) \\
Void in mineral aggregate & 14 (minimum) \\
Void filled with asphalt & $70-80$ \\
Air void $(\%)$ & $3.0-5.0$ \\
Flow $(\mathrm{mm})$ & $2.0-4.0$ \\
\hline
\end{tabular}

\subsection{Laboratory Evaluation}

Based on the optimum asphalt level obtained from the Marshall mix design, the specimens are prepared for different tests following the specification and standard. The tests carried out in the study are described below:

\subsubsection{Indirect Tensile Strength}

The tensile property is an important parameter that plays a significant role to identify the cracking behavior of asphalt pavement. Indirect tensile strength (ITS) is considered as one of the fundamental tests that indicate resistance to different failure types such as intermediate temperature fatigue cracking $[28,29]$, etc. So, identifying ITS will be an important parameter for waste oil rejuvenated mixtures. The ITS value is measured at a temperature of $25^{\circ} \mathrm{C}$ following the ASTM D6931. At the experimental setup, the cylindrical sample (101-mm diameter) experiences uniform tensile stress $(51 \mathrm{~mm} / \mathrm{min}$ ) across the diametrical axis tensile force until it fails. The tensile strength at failure point is calculated using the equation below:

$\mathrm{ITS}=P_{\max } / 3.1416 \times H \times D$

here, $P_{\max }$ is the maximum applicable load and $H$ and $D$ are the height and diameter of the sample, respectively.

\subsubsection{Resilient Modulus}

Resilient modulus $\left(\mathrm{M}_{\mathrm{R}}\right)$ dictates the load-carrying ability and resistance to rutting of the asphalt pavement [30, 31]. Previous studies concluded the change in percentage of recycling agent and RAP in the mixture can regulate the $M_{R}$ values [32]. So, the test is expected to dictate an important indication for the desired mixture. In this study, the test is conducted on the $25^{\circ} \mathrm{C}$ temperature with $0.33 \mathrm{~Hz}$ loading frequency based on ASTM D-4123. The $\mathrm{M}_{\mathrm{R}}$ of the mixture is measured by simulating the dynamics of the traffic by a computer-based waveform. The simulation is carried out by "Servo-Pneumatic Universal Testing Machine".

\subsubsection{Durability}

The durability of the asphalt pavement is measured by evaluating the resistance to the adverse effects of the environment [33]. One of the significant environmental factors that jeopardize the performance of the flexible pavement is moisture [34]. Of the numerous numbers of distress that an asphalt pavement experiences during its service life, moisture is regarded as one of the significant factors that subsequently results in the failure of asphalt pavement $[35,36]$. The safe performance of a structure for the specified life expectancy depends on increasing durability against water-induced damage. The use of RAP in the mixtures reduces the moisture damage [37], whereas the inverse was also concluded by another study [38, 39]. In this study, the moisture susceptibility (durability) is assessed following the AASHTO T245 method. To analyze the results, the average wet and dry tensile strength of the specimens known as the tensile strength ratio (TSR) is considered.

$\mathrm{TSR}=\mathrm{ITS}_{\mathrm{wet}} / \mathrm{ITS}_{\mathrm{dry}}$

Here, ITS wet $_{\text {and }}$ ITS $_{\text {dry }}$ are the ITS values of the wet and dry samples, respectively, and the recommended minimum value is $80 \%$. 
Fig. 2 ITS values of SM, CRM, $\mathrm{EOM}$ and $\mathrm{COM}$ for various combination of RAP a $30 \%$, b $40 \%$, and c $50 \%$
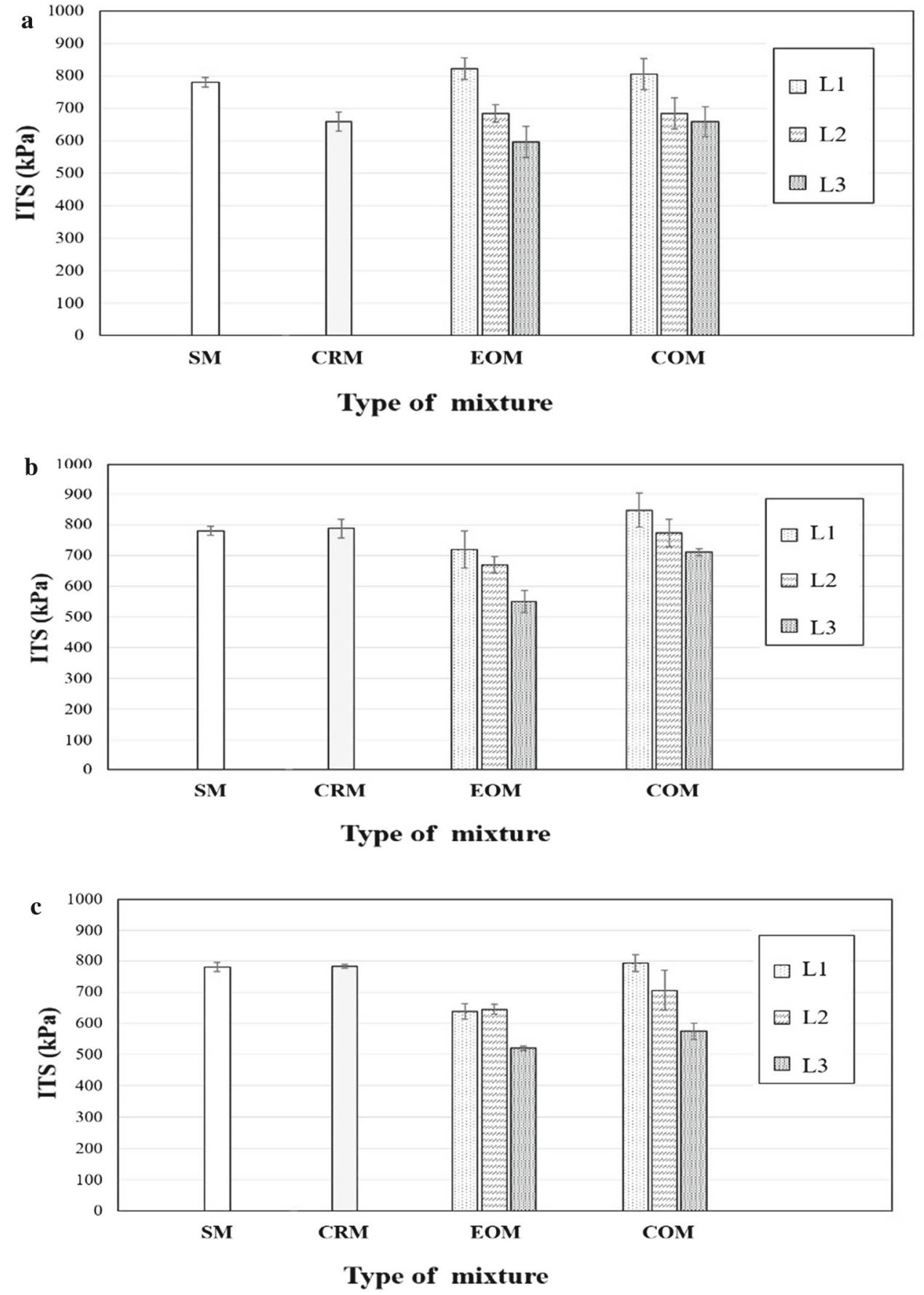

\section{Results}

The tests mentioned above are carried out to evaluate the effectiveness of different properties of CR, WEO and WCO rejuvenated mixtures and are compared to the mixtures without any RAP denoted as SM. The comparison is discussed in two different sections.

\subsection{Graphical Analysis}

The effect of percentage rejuvenators for different percentages of RAP is visualized. Here, the mixtures rejuvenated by CR, WEO and WCO are denoted as CRM, EOM, and COM respectively. Three different levels of rejuvenators are denoted as L1, L2, L3, where L1 represents the lowest percentage of the corresponding rejuvenator and L3 indicates the highest percentage of the rejuvenator. 
Fig. $3 \mathrm{M}_{\mathrm{R}}$ values of $\mathrm{SM}, \mathrm{CRM}$, $\mathrm{EOM}$, and COM for various combination of RAP a $30 \%$, b $40 \%$, and c $50 \%$
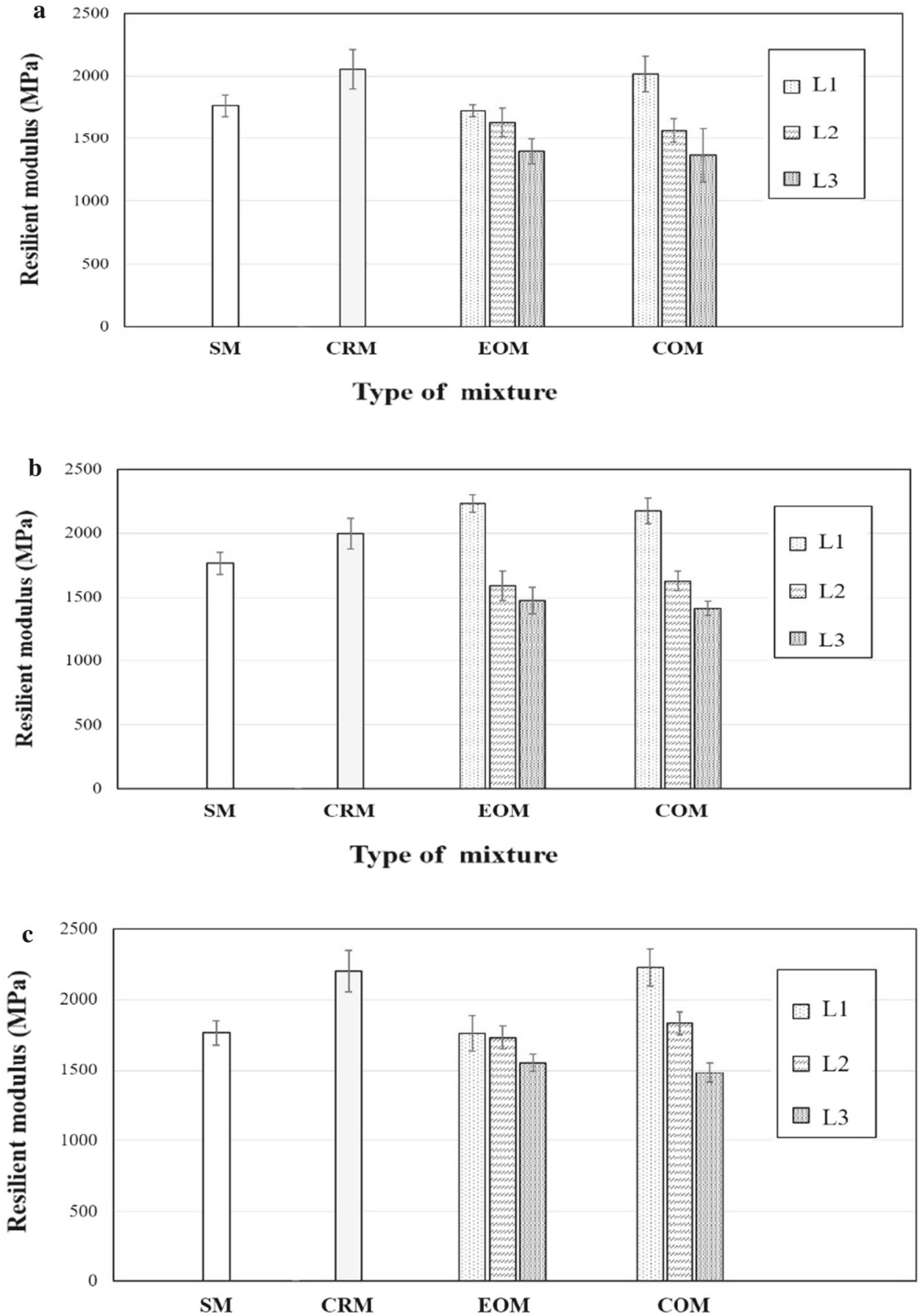

Type of mixture

\subsubsection{Effect of RAP and Rejuvenator on ITS}

Figure 2 depicts the ITS values of EOM and COM mixtures at different rejuvenator levels and are compared to SM and CRM.
The figure shows that the percentage and type of rejuvenator and the percentage of RAP are significantly affecting the ITS values of the mixtures. The increase in the percentage of rejuvenator (L1-L3) for WCO and WEO results in a decrease in ITS value. This usual tendency of decreasing the ITS values is observed for both EOM and COM regardless of the 
Fig. 4 TSR values of SM, CRM, EOM, and COM for various combinations of RAP a $30 \%$, b $40 \%$, and c $50 \%$
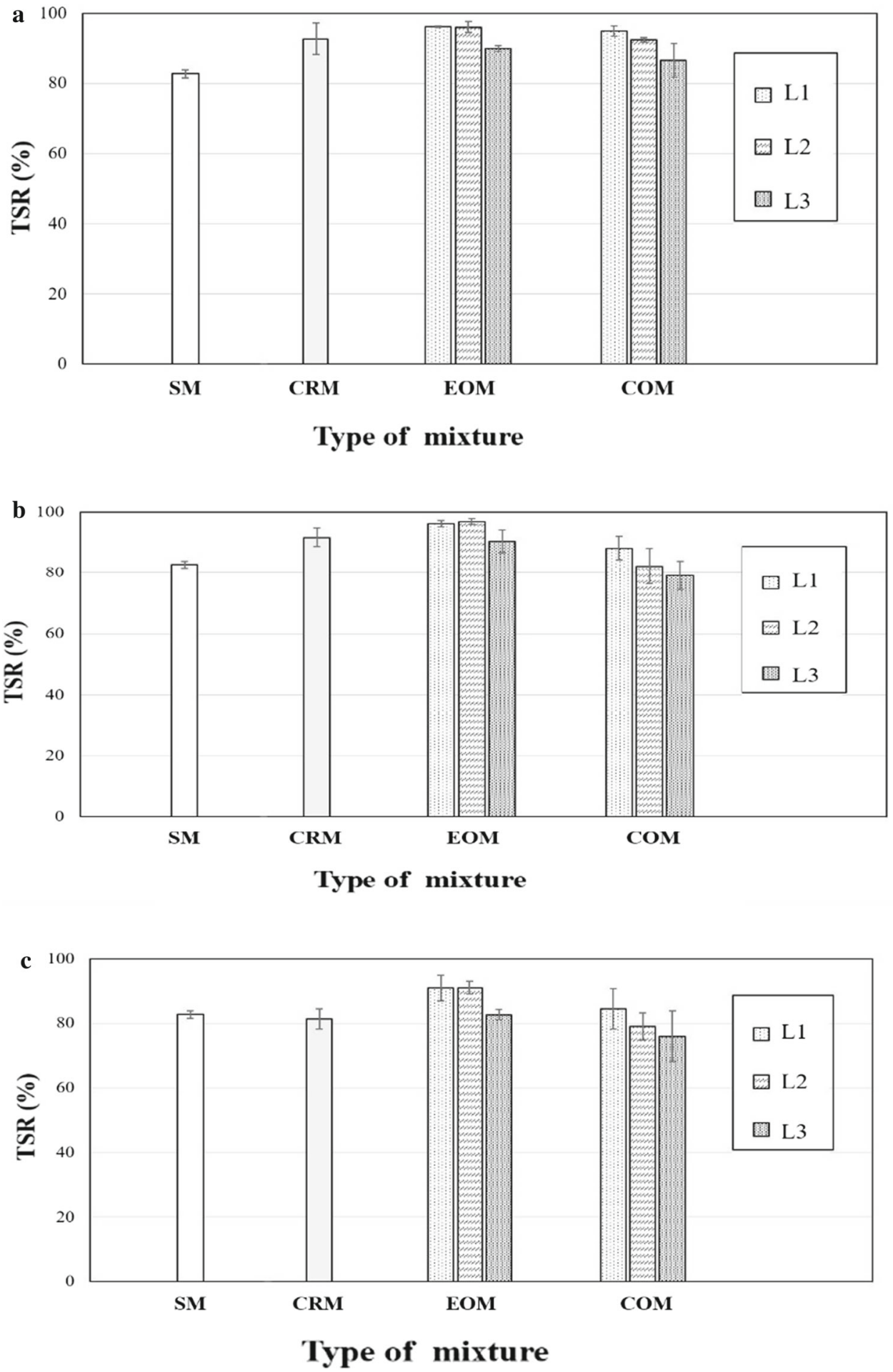

percentage of RAP in the mixtures. The increased percentage of rejuvenators results in a softer binder by decreasing the viscosity and results in a lower adhesion capacity which could lessen the ITS values. In addition to that, the increased percentage of RAP also reduces ITS values. However, the decreasing rate for EOM and COM is different. For any per- centage of RAP and rejuvenator, COM shows higher ITS values than the corresponding EOM. Incoherent bonding with the fresh ingredients due to increased RAP could lead to a less homogeneous mixture and subsequently resulted in lower ITS. 


\subsubsection{Effect of RAP and Rejuvenator on $M_{R}$}

In Fig. 3, the effect of percentages of RAP and rejuvenator on $\mathrm{M}_{\mathrm{R}}$ for the CRM, EOM, and COM mixtures are depicted and compared to SM.

The mixture with $40 \%$ of RAP and rejuvenated by the L1 percentage of WEO is comparable to the SM and CRM. On the contrary, all the mixtures rejuvenated by $\mathrm{L} 1$ and $\mathrm{L} 2$ percentages of WCO are comparable to SM and CRM. For any percentage of RAP and rejuvenator, COM shows comparatively higher $M_{R}$ values than the corresponding EOM. The shift in rejuvenator percentages from $\mathrm{L} 1$ to $\mathrm{L} 3$ decreases the $M_{R}$ values. However, the rate of decrease is different for EOM and COM. The increased rejuvenators result in a soft mixture, and consequently, the softening effect of the rejuvenators is expected to decrease the $M_{R}$ values. The higher percentages of RAP raised the $M_{R}$ of the mixture due to the stiff nature of the aged RAP. The increased percentage of RAP could lead to a less homogeneous mixture and subsequently resulted in lower $\mathrm{M}_{R}$ values. Overall, the combined increment in rejuvenator and RAP show dual effects: the hardening effect of RAP and the softening effect of rejuvenators.

\subsubsection{Effect of RAP and Rejuvenator on TSR}

The TSR values of different mixtures can be observed in Fig. 4.

It is observed that the susceptibility to moisture damage increases due to the increased percentages of RAP and rejuvenators in mixtures. For both rejuvenators, the mixtures rejuvenated by L1 and L2 are comparable to those of SM and CRM. However, after $40 \%$ of RAP in the mixtures, the L3 level provides a TSR value very close to the permissible limit indicating lower durability due to the increased percentages of rejuvenators in the mixtures. It is expected that lower cohesion and adhesion due to the higher percentages of rejuvenators will increase moisture damage [40]. Similarly, the increased percentages of RAP also reduce TSR values, yet the mixtures passed the criterion of minimum TSR in most of the cases. Although the presence of RAP has increased the durability comparatively, its gradual increment negatively affects the mixtures due to less cohesion with the fresh ingredients and subsequently resulted in lower TSR values.

\subsection{Numerical Analysis}

The effect of the percentage of rejuvenators, RAP and rejuvenator type is evaluated statistically and is ranked in the subsequent section. COM and EOM are denoted based on their percentage of rejuvenator, i.e., COM-13 specifies the mixture rejuvenated by $13 \%$ of WCO.
Table $5 P$ values obtained by analysis of variances (ANOVA)

\begin{tabular}{llll}
\hline Percentage of RAP & ITS & M $_{R}$ & TSR \\
\hline Mixture type & 0.000 & 0.081 & 0.000 \\
Percentage of RAP (mixture type) & 0.000 & 0.005 & 0.000 \\
Percentage of Rejuvenator (mixture type) & 0.000 & 0.000 & 0.000 \\
\hline
\end{tabular}

\subsubsection{Statistical Evaluation}

The effect of the percentage of RAP and rejuvenator and the type of rejuvenator in different types of tests are evaluated using the analysis of variances (ANOVA). The evaluation is based on a marginal $P$ value of .05 , indicating that factors with a $P$ value less than .05 are significant. Table 5 indicates that the percentage of RAP and rejuvenation affected all the desired properties significantly.

The type of rejuvenator (WCO/WEO) affects all properties except $M_{R}$. The results of ANOVA also show that the WCO and WEO have a different effect on the mixture; however, it cannot be inferred which of them should be prioritized according to their characteristics.

\subsubsection{Ranking of EOM and COM}

The discussion above indicates the effectiveness of WCO and WEO for different percentages of RAP. However, the rejuvenation capacity of these waste oils is subject to change following the percentages of RAP, rejuvenator percentage and type of test. Therefore, for a certain percentage of RAP, the most effective rejuvenator and corresponding percentage need to be addressed. Here, the mixtures are grouped based on the percentages of RAP (Table 6).

For a certain percentage of RAP, EOM and COM are compared to CRM and SM and ranked according to the obtained properties. The most effective mixture is ranked as 1 , whereas the least effective mixture is ranked as 8 . For example, for $30 \%$ RAP mixture, EOM-7 shows an average ITS value of $822 \mathrm{kPa}$ and outperformed the other mixtures, and therefore it was ranked 1. However, for 30\% RAP mixture, EOM-7 shows an average $M_{R}$ value of $1726 \mathrm{MPa}$ which is less than the observed $M_{R}$ values of CRM, COM-13, and SM and therefore it was ranked 4. Similarly, the ranking of the mixtures was carried out for $40 \%$ and $50 \%$ of RAP mixtures. It is to be mentioned that Table 6 indicates the rounded values for the ITS and $\mathrm{M}_{\mathrm{R}}$ and up to two digits for the TSR, however, the ranking was carried out based on the actual values. It is observed that the properties of any of the mixtures are subject to change following the test. Therefore, to evaluate the overall effectiveness of any of the mixtures, it needs to be ranked for the observed properties which can be observed in Table 7. 
Table 6 Ranking of mixtures for different percentages of RAP

\begin{tabular}{|c|c|c|c|c|c|c|c|}
\hline Percent of RAP & Mixture type & ITS $(\mathrm{kPa})$ & Ranking & $\mathrm{M}_{\mathrm{R}}(\mathrm{MPa})$ & Ranking & TSR (\%) & Ranking \\
\hline \multirow[t]{8}{*}{30} & $\mathrm{SM}$ & 780 & 3 & 1765 & 3 & 82.73 & 8 \\
\hline & CRM & 658 & 7 & 2054 & 1 & 92.67 & 4 \\
\hline & EOM-7 & 822 & 1 & 1726 & 4 & 96.17 & 1 \\
\hline & EOM-13 & 683 & 4 & 1629 & 5 & 96.00 & 2 \\
\hline & EOM-20 & 596 & 8 & 1398 & 7 & 89.83 & 6 \\
\hline & COM-13 & 805 & 2 & 2017 & 2 & 94.83 & 3 \\
\hline & COM-20 & 683 & 5 & 1566 & 6 & 92.38 & 5 \\
\hline & COM-27 & 659 & 6 & 1366 & 8 & 86.52 & 7 \\
\hline \multirow[t]{8}{*}{40} & SM & 780 & 3 & 1765 & 4 & 82.73 & 6 \\
\hline & CRM & 787 & 2 & 1998 & 3 & 91.67 & 3 \\
\hline & EOM-7 & 719 & 5 & 2231 & 1 & 96.83 & 1 \\
\hline & EOM-13 & 669 & 7 & 1591 & 6 & 96.17 & 2 \\
\hline & EOM-20 & 551 & 8 & 1476 & 7 & 90.33 & 4 \\
\hline & COM-13 & 848 & 1 & 2173 & 2 & 88.11 & 5 \\
\hline & COM-20 & 773 & 4 & 1627 & 5 & 82.13 & 7 \\
\hline & COM-27 & 710 & 6 & 1413 & 8 & 79.08 & 8 \\
\hline \multirow[t]{8}{*}{50} & SM & 780 & 3 & 1765 & 4 & 82.73 & 4 \\
\hline & CRM & 781 & 2 & 2198 & 2 & 81.33 & 6 \\
\hline & EOM-7 & 645 & 5 & 1762 & 5 & 91.00 & 2 \\
\hline & EOM-13 & 638 & 6 & 1733 & 6 & 91.00 & 1 \\
\hline & EOM-20 & 520 & 8 & 1555 & 7 & 82.67 & 5 \\
\hline & COM-13 & 792 & 1 & 2227 & 1 & 84.46 & 3 \\
\hline & COM-20 & 705 & 4 & 1833 & 3 & 78.94 & 7 \\
\hline & COM-27 & 574 & 7 & 1482 & 8 & 75.97 & 8 \\
\hline
\end{tabular}

Hence, the overall ranking of the mixtures was carried out by summing the observed ranking for each test. Finally, the mixture with the least summation value was ranked as 1 . For example, for $30 \%$ RAP mixture, the summation of ranking for the EOM-7 is 6 and the overall ranking is 1 . For a certain percentage of RAP, any of the waste oil rejuvenated mixtures ranked as less than SM is considered as an effective mixture. The table indicates that for $30 \%$ of RAP, EOM-7 outperforms all the mixtures and the mixtures with $13 \%$ of $\mathrm{WCO}$ and 13 to $20 \%$ of WEO provide better characteristics than SM. Similarly, for $40 \%$ of RAP, EOM-7 outperforms all the mixtures, whereas COM-13 provides better characteristics than SM and are comparable to CRM. However, COM-13 outperforms all the mixtures for $50 \%$ of RAP and for $50 \%$ RAP, the overall characteristics of EOM are less satisfactory than the SM and CRM.

\section{Conclusions and Recommendation}

The effectiveness of different percentages of RAP and waste oil (WCO and WEO) was evaluated for different types of tests and is compared to SM and CRM. Based on the analysis of observed results, the following conclusions are made:

1. The mixtures with $7 \%$ of WEO outperformed all the other mixtures for $30 \%$ of RAP mixtures. The mixtures rejuvenated by $13 \%$ of $\mathrm{WEO}$ and $\mathrm{WCO}$ provide better performance than SM and CRM.

2. The mixtures with $7 \%$ of WEO provide better performance than all the other mixtures for $40 \%$ of RAP. The mixtures rejuvenated by $13 \%$ of $\mathrm{WCO}$ provide better performance than SM and are comparable to the CR rejuvenated mixtures. The mixtures rejuvenated by $13 \%$ of WCO outperformed all the other mixtures for $50 \%$ of RAP mixtures.

3. Overall, $7 \%$ of WEO can be used until $40 \%$ of RAP, whereas $13 \%$ of WCO can be used until $50 \%$ of RAP. However, an extensive comparison based on advanced performance tests such as fatigue and rutting is also recommended.

4. The constituent of waste oil may affect the phase integrity, new bonding capacity, and crystalline structure of the fresh and aged asphalt. A nanoscale evaluation of 
Table 7 Final ranking of the mixtures for different percentages of RAP

\begin{tabular}{|c|c|c|c|}
\hline Percent of RAP & Mixture type & $\begin{array}{l}\text { Summation of } \\
\text { ranking }\end{array}$ & Overall ranking \\
\hline \multirow[t]{8}{*}{30} & SM & 14 & 5 \\
\hline & CRM & 12 & 4 \\
\hline & EOM-7 & 6 & 1 \\
\hline & EOM-13 & 11 & 3 \\
\hline & EOM-20 & 21 & $7-8$ \\
\hline & COM-13 & 7 & 2 \\
\hline & COM-20 & 16 & 6 \\
\hline & COM-27 & 21 & $7-8$ \\
\hline \multirow[t]{8}{*}{40} & SM & 13 & 4 \\
\hline & CRM & 8 & $2-3$ \\
\hline & EOM-7 & 7 & 1 \\
\hline & EOM-13 & 15 & 5 \\
\hline & EOM-20 & 19 & 7 \\
\hline & COM-13 & 8 & $2-3$ \\
\hline & COM-20 & 16 & 6 \\
\hline & COM-27 & 22 & 8 \\
\hline \multirow[t]{8}{*}{50} & SM & 11 & 3 \\
\hline & CRM & 10 & 2 \\
\hline & EOM-7 & 12 & 4 \\
\hline & EOM-13 & 13 & 5 \\
\hline & EOM-20 & 20 & 7 \\
\hline & COM-13 & 5 & 1 \\
\hline & COM-20 & 14 & 6 \\
\hline & COM-27 & 23 & 8 \\
\hline
\end{tabular}

these factors can provide more insight into the waste oil rejuvenated asphalt binder. In addition to that, a thorough economic analysis is required before applying waste oil rejuvenated asphalt in the industry; therefore, a Life Cycle Cost Analysis (LCCA) of aged asphalt rejuvenated by WCO and WEO is recommended.

\begin{abstract}
Acknowledgements Open Access funding provided by the Qatar National Library. The authors would like to thank Qatar University, King Fahd University of Petroleum and Minerals (KFUPM), and Imam Abdulrahman Bin Faisal University for supporting this study. Special thanks to Engr. G. Baig of KFUPM for his guidance in ignition furnace maneuver assistance during the course of the study.
\end{abstract}

Open Access This article is licensed under a Creative Commons Attribution 4.0 International License, which permits use, sharing, adaptation, distribution and reproduction in any medium or format, as long as you give appropriate credit to the original author(s) and the source, provide a link to the Creative Commons licence, and indicate if changes were made. The images or other third party material in this article are included in the article's Creative Commons licence, unless indicated otherwise in a credit line to the material. If material is not included in the article's Creative Commons licence and your intended use is not permitted by statutory regulation or exceeds the permitted use, you will need to obtain permission directly from the copy- right holder. To view a copy of this licence, visit http://creativecomm ons.org/licenses/by/4.0/.

\section{References}

1. Giani, M.I.; Dotelli, G.; Brandini, N.; Zampori, L.: Comparative life cycle assessment of asphalt pavements using reclaimed asphalt, warm mix technology and cold in-place recycling. Resour. Conserv. Recycl. 104, 224-238 (2015). https://doi.org/10.1016/j.resconrec. 2015.08.006

2. Jahanbakhsh, H.; Karimi, M.M.; Naseri, H.; Nejad, F.M.: Sustainable asphalt concrete containing high reclaimed asphalt pavements and recycling agents: performance assessment, cost analysis, and environmental impact. J. Clean. Prod. 244, 118837 (2020). https:// doi.org/10.1016/j.jclepro.2019.118837

3. Zaumanisa, M.; Mallicka, R.B.; Frankb, R.: 100\% recycled hot mix asphalt: a review and analysis. Resour. Conserv. Recycl. 92, 230-245 (2014). https://doi.org/10.1016/j.resconrec.2014.07.007

4. Mamun, A.; Arifuzzaman, M.; Taha, R.: Nano scale aging characterization of carbon nanotube modified asphalt binders. In: Advances in Materials and Pavement Prediction: Papers from the International Conference on Advances in Materials and Pavement Performance Prediction (am3p 2018), 16-18 Apr 2018, Doha, Qatar, p. 403 (2018)

5. Mogawer, W.; Bennert, T.; Daniel, J.S.; Bonaquist, R.; Austerman, A.; Booshehrian, A.: Performance characteristics of plant produced high rap mixtures. Road Mater. Pavement Des. 13(sup1), 183-208 (2012)

6. Lins, V.; Araújo, M.; Yoshida, M.; Ferraz, V.; Andrada, D.; Lameiras, F.: Photodegradation of hot-mix asphalt. Fuel 87(15-16), 3254-3261 (2008)

7. García, A.; Schlangen, E.; Van de Ven, M.: Properties of capsules containing rejuvenators for their use in asphalt concrete. Fuel 90(2), 583-591 (2011)

8. Antunes, V.; Freire, A.C.; Neves, J.: A review on the effect of RAP recycling on bituminous mixtures properties and the viability of multi-recycling. Constr. Build. Mater. 211, 453-469 (2019). https:// doi.org/10.1016/j.conbuildmat.2019.03.258

9. Devulapalli, L.; Kothandaraman, S.; Sarang, G.: Evaluation of rejuvenator's effectiveness on the reclaimed asphalt pavement incorporated stone matrix asphalt mixtures. Constr. Build. Mater. 224, 909-919 (2019). https://doi.org/10.1016/j.conbuildmat.2019. 07.126

10. Hugener, M.; Partl, M.N.; Morant, M.: Cold asphalt recycling with $100 \%$ reclaimed asphalt pavement and vegetable oil-based rejuvenators. Road Mater. Pavement Des. 15(2), 239-258 (2014). https:// doi.org/10.1080/14680629.2013.860910

11. Jia, X.; Huang, B.; Moore, J.A.; Zhao, S.: Influence of waste engine oil on asphalt mixtures containing reclaimed asphalt pavement. J. Mater. Civ. Eng. 27(12), 04015042 (2015). https://doi.org/10.106 1/(ASCE)MT.1943-5533.0001292

12. Li, Y.; Shen, A.; Lyu, Z.; Wang, S.; Formela, K.; Zhang, G.: Ground tire rubber thermo-mechanically devulcanized in the presence of waste engine oil as asphalt modifier. Constr. Build. Mater. 222, 588-600 (2019). https://doi.org/10.1016/j.conbuildmat.2019.06.1 62

13. Mamun, A.A.; Wahhab, H.I.A.-A.: Comparative laboratory evaluation of waste cooking oil rejuvenated asphalt concrete mixtures for high contents of reclaimed asphalt pavement. Int. J. Pavement Eng. (2018). https://doi.org/10.1080/10298436.2018.1539486

14. Taherkhani, H.; Noorian, F.: Laboratory investigation on the properties of asphalt concrete containing reclaimed asphalt pavement and waste cooking oil as recycling agent. Int. J. Pavement Eng. (2019). https://doi.org/10.1080/10298436.2019.1626387 
15. Xingyu, Y.; Ruikun, D.; Naipeng, T.: Development of a novel binder rejuvenator composed by waste cooking oil and crumb tire rubber. Constr. Build. Mater. 236, 117621 (2020). https://doi.org/10.1016/ j.conbuildmat.2019.117621

16. Zhang, J.; Sun, H.; Jiang, H.; Xu, X.; Liang, M.; Hou, Y.; et al.: Experimental assessment of reclaimed bitumen and RAP asphalt mixtures incorporating a developed rejuvenator. Constr. Build. Mater. 215, 660-669 (2019). https://doi.org/10.1016/j. conbuildmat.2019.04.202

17. Ziari, H.; Moniri, A.; Bahri, P.; Saghafi, Y.: The effect of rejuvenators on the aging resistance of recycled asphalt mixtures. Constr. Build. Mater. 224, 89-98 (2019). https://doi.org/10.1016/ j.conbuildmat.2019.06.181

18. Ziari, H.; Moniri, A.; Bahri, P.; Saghafi, Y.: Evaluation of performance properties of 50\% recycled asphalt mixtures using three types of rejuvenators. Pet. Sci. Technol. 37(23), 2355-2361 (2019). https://doi.org/10.1080/10916466.2018.1550505

19. Borhan, M.N.; Suja, E.; Ismail, A.; Rahmat, R.A.O.: Used cylinder oil modified coldmix asphalt concrete. J. Appl. Sci. 7(22), 3485-3491 (2007)

20. DeDene, C.D.; You, Z.-P.: The performance of aged asphalt materials rejuvenated with waste engine oil. Int. J. Pavement Res. Technol. 7(2), 145-152 (2014)

21. Tran, N.H., Taylor, A.,; Willis, R.: Effect of rejuvenator on performance properties of HMA mixtures with high RAP and RAS contents. NCAT Report, 12-05 (2012)

22. Roberts, F.L.; Kandhal, P.S.; Brown, E.R.; Lee, D.-Y.; Kennedy, T.W.: Hot Mix Asphalt Materials, Mixture Design and Construction (1991)

23. Taherkhania, H.; Noorianb, F.: Comparing the effects of waste engine and cooking oil on the properties of asphalt concrete containing reclaimed asphalt pavement (RAP). Road Mater. Pavement Des. (2018). https://doi.org/10.1080/14680629.2018.1546220

24. El-Shorbagy, A.M.; El-Badawy, S.M.; Gabr, A.R.: Investigation of waste oils as rejuvenators of aged bitumen for sustainable pavement. Constr. Build. Mater. 220, 228-237 (2019). https://doi.org/1 0.1016/j.conbuildmat.2019.05.180

25. Mamun, A.A.; Al-Abdul Wahhab, H.I.: Evaluation of waste engine oil-rejuvenated asphalt concrete mixtures with high RAP content. Adv. Mater. Sci. Eng. 2018, 7386256 (2018). https://doi.org/10.11 55/2018/7386256

26. Boriack, P.C.; Katicha, S.W.; Flintsch, G.W.; Tomlinson, C.R.: Laboratory evaluation of asphalt concrete mixtures containing high contents of reclaimed asphalt pavement (rap) and binder (Tech. Rep.). Virginia Center for Transportation Innovation and Research (2014)

27. Daniel, J.; Lachance, A.: Mechanistic and volumetric properties of asphalt mixtures with recycled asphalt pavement. Transp. Res. Rec. J. Transp. Res. Board 1929, 28-36 (2005)
28. Zhang, Z.; Rogue, R.; Birgisson, B.; Sangpetngam, B.: Identification and verification of a suitable crack growth law. J. Assoc. Asphalt Paving Technol. 70, 206-241 (2001)

29. Huang, B.; Li, G.; Mohammad, L.N.: Analytical modeling and experimental study of tensile strength of asphalt concrete composite at low temperatures. Compos. B Eng. 34(8), 705-714 (2003)

30. Putri, A.M.; Suparma, L.B.: Laboratory study on the durability characteristics (moisture damage evaluation) of asphalt concrete wearing course (ac-wc) utilizing bantak and clereng as aggregate (using Marshall methods). J. East. Asia Soc. Transp. Stud. 8, 1555-1567 (2010)

31. Mashaan, N.S.; Karim, M.R.: Evaluation of permanent deformation of CRM-reinforced SMA and its correlation with dynamic stiffness and dynamic creep. Sci. World J. 2013, 981637 (2013)

32. Sondag, M.S.; Chadbourn, B.A.; Drescher, A.: Investigation of recycled asphalt pavement (RAP) mixtures (2002)

33. Puga, N.; Nieve, K.L.: Rheology and performance evaluation of polyoctenamer as asphalt rubber modifier in hot mix asphalt (2013)

34. Arifuzzaman, M.; Gazder, U.; Islam, M.S.; Mamun, A.A.: Prediction and sensitivity analysis of CNTs-modified asphalt's adhesion force using a radial basis neural network model. J. Adhes. Sci. Technol. 34(10), 1-15 (2019)

35. Hassan, M.R.; Mamun, A.A.; Hossain, M.I.; Arifuzzaman, M.: Moisture damage modeling in lime and chemically modified asphalt at nanolevel using ensemble computational intelligence. Comput. Intell. Neurosci. 2018, 7525789 (2018)

36. Mamun, A.; Arifuzzaman, M.: Nano-scale moisture damage evaluation of carbon nanotube-modified asphalt. Constr. Build. Mater. 193, 268-275 (2018)

37. Doyle, J.D.; Howard, I.L.: Rutting and moisture damage resistance of high reclaimed asphalt pavement warm mixed asphalt: loaded wheel tracking vs. conventional methods. Road Mater. Pavement Des. 14(sup2), 148-172 (2013)

38. Huang, B.; Shu, X.; Vukosavljevic, D.: Laboratory investigation of cracking resistance of hot-mix asphalt field mixtures containing screened reclaimed asphalt pavement. J. Mater. Civ. Eng. 23(11), 1535-1543 (2010)

39. MoghadasNejad, F.; Azarhoosh, A.; Hamedi, G.H.; Roshani, H.: Rutting performance prediction of warm mix asphalt containing reclaimed asphalt pavements. Road Mater. Pavement Des. 15(1), 207-219 (2014)

40. Zaumanis, M.; Mallick, R.B.; Poulikakos, L.; Frank, R.: Influence of six rejuvenators on the performance properties of reclaimed asphalt pavement (rap) binder and $100 \%$ recycled asphalt mixtures. Constr. Build. Mater. 71, 538-550 (2014) 